\title{
Reescribiendo
}

\section{la historia de}

la conquista

española: Mitos

fundacionales en

\section{los Comentarios}

\section{Reales de los Incas}

Evelyn Saavedra Autry

Recebido em: 8 de outubro de 2018

Aceito em: 28 de novembro de 2018
Candidata al doctorado en Letras por la University of Georgia, EE.UU. Se especializa en la novela indigenista y del conflicto armado interno peruano. Es autora de "Magda Portal: procesos de modernización, vanguardismo y compromiso", "El pobre más rico: heterogeneidad y transculturación en el teatro quechua colonial", "Testimonio, ficción y las batallas por las memorias en Insensatez de Horacio Castellano Moya", entre otros.

Contacto: evelyn.autry@uga.edu Estados Unidos 


\section{PALABRAS CLAVE:}

Literatura peruana; Inca

Garcilaso de la Vega; historia indígena; mitos fundacionales; oralidad quechua

\section{KEYWORDS: Peruvian} literatura; Inca Garcilaso de la Vega; indigenous history; foundational myths; Quechua orality
Resumen: Los Comentarios Reales del Inca Garcilaso de la Vega ofrece una narrativa alterna de la historia del Perú y del imperio incaico antes y durante la conquista. Para justificar su concepto de verdad, Garcilaso emplea herramientas retóricas que le permiten servirse de la escritura española y la oralidad quechua. A partir de la reescritura de historias de los cronistas españoles, las cuales defino como mitos y no fábulas, Garcilaso cuestiona la veracidad de esas crónicas y corrige la historia que proponen sobre el incario. Exploro cómo Garcilaso y su retórica edifican los cimientos de la historia de los Incas, justificándose en la autoridad que le brindan el discurso oral y sus conocimientos de los mitos incaicos. Los Comentarios Reales no serían "la más perfecta síntesis entre historia y ficción" (Arias Carbone), sino una continua nesociación entre la autoridad de la historia y una ficción referida como fábula. El proyecto de Garcilaso fue historizar el imaginario incaico y establecer un mito fundacional incaico.

Abstract: The Comentarios Reales, written by Inca Garcilaso de la Vesa, offers an alternative narrative concerning the Incan Empire and Peruvian colonial history before and during the Spanish conquest. To justify his concept of truth, Garcilaso uses rhetorical devices that allow him to utilize Spanish writing intertwined with Quechua orality. From the rewriting of Spanish chroniclers' stories about the Incan Empire, which I define as myths and not fables, Garcilaso questions the veracity of the chronicles and corrects the Andean history. I explore how Garcilaso and his rhetorical devices build the foundations for Incan history while justifying himself in the authority oral discourse and knowledge of the Inca myths. The Comentarios Reales is not the most perfect synthesis between history and fiction (Arias Carbone), but a continuous negotiation between the authority of history and a fiction referred to as fables. The project of Garcilaso was to historicize the Incan imaginary and establish a foundational Incan myth. 
Los Comentarios Reales de los Incas del mestizo Inca Garcilaso de la Vega primera vez publicado en el ańo 1609, ofrece una narrativa alterna de la historia del Perú y el imperio incaico antes y durante la invasión y conquista española. Para justificar su concepto de verdad, Garcilaso emplea herramientas retóricas que le permiten servirse de la escritura española y la oralidad quechua para reconquistar discursos escritos y orales. A partir de la reescritura de historias de los cronistas españoles sobre el imperio incaico, las cuales defino como mitos y no fábulas, Garcilaso cuestiona la veracidad de las crónicas escritas por cronistas espańoles y corrige la historia que ellos proponen sobre las costumbres y prácticas del incario. En este ensayo exploro cómo Garcilaso y el uso de sus herramientas retóricas edifican los cimientos de la historia de los Incas, justificándose en la autoridad que le brindan el discurso oral y sus conocimientos de los mitos incaicos narrados por los Amautas. Específicamente, propongo que los Comentarios Reales de los Incas no son una bifurcación de "la más perfecta síntesis entre historia y ficción" (Arias Carbone, p.7), sino una continua negociación entre la autoridad de la historia y ficción referidas como fábulas. El proyecto del Inca es historizar el imaginario incaico, reescribirlo y establecer los cimientos de un mito fundacional incaico.

El desarrollo de esta propuesta, parte del análisis del proceso de textualización de las fábulas y mitos que establecen el discurso del mito fundacional de Manco Capac y Mama Oclloº así como en las fábulas

1 Tómese en cuenta que en los Comentarios reales Garcilaso ofrece tres versiones del origen de los Incas. Entre ellas se encuentran el mito de los cuatro hermanos Ayar, el mito de Manco 
de viajeros y la versión del Padre José de Acosta sobre la llegada de un marinero a las Américas antes de Cristóbal Colón. Con este fin, entablaré un dialogo con las teorías sobre el mito y la fábula, argumentadas por Mircea Eliade y Juan Carlos Dido, respectivamente, para así mantener una línea divisoria entre las alegorías que edifican el mito y aquellas que construyen la fábula de los viajeros. Con la finalidad de construir un marco teórico, desde donde elaborar una lectura productiva, incluiré el ensayo "Fábulas clásicas y neoplatónicas en los Comentarios reales de los Incas" de Efraín Krystal, The narrow pass of our nerves. Writing coloniality and postcolonial theory de Sara Klaren Castro, "Los mitos de origen de los Incas en la construcción de los Comentarios reales" de Juan Ossio y "Reading Colonialism in Garcilaso's Historia General del Perü" de Margarita Zamora, entre otros.

Garcilaso, nace con el nombre de Gómez Suárez de Figueroa, hijo de una princesa incaica y un conquistador español (Vargas Llosa, p.19), quien encuentra en su bilingüismo quechua y español la autoridad de forjar una historia. La escritura de Garcilaso, la cual se justifica en el yo narrativo, la narración testimonial, su conocimiento de la historia referida por cronistas europeos, el contacto con mentores jesuitas y su familia incaica y española, así como el conocimiento que tenía Garcilaso sobre tres culturas divergentes: la del Inca, del Perú en el proceso de colonización y mestizaje y la espańola, le permitieron problematizar la veracidad de las crónicas

Capac y Mama Ocllo que proviene de Del Collasuyo y Contisuo (Ossio, p.68) y la tercera que es analizada en este trabajo. 
europeas que historizaban las indias. El cuestionamiento de la autoridad de la historia escrita por Juan de Betanzos, Gregario García, Sarmiento de Gamboa, Francisco López de Gómara, Pedro de Cieza de León, El clérigo anónimo, Cristóbal de Molina, José de Acosta, Bernabé Cobo, entre otros (Durand, p.9-18), añade otra capa alegórica a la historia que inscribe Garcilaso, y cuya herramienta, digamos hasta subversiva, reconquista el uso del discurso escrito a través del discurso oral.

Una de las peculiaridades de la crónica de Garcilaso es la incorporación y corrección del quechua, lo cual refleja una de las características del humanismo y ese afán de rescatar y reconstruir la lengua antigua (Zamora, p.16-17). El conocimiento y dominio de este idioma le permite cuestionar-sin hacerlo directamente-a los cronistas españoles y al imaginario del imperio incaico que los cronistas historizaban. En primera persona Garcilaso narra, "yo protesto decir llanamente la relación que mamé en la leche y la que después acá he habido, pedida a los propios míos [...] y no escribiré novedades que no se hayan oído, sino las mismas cosas que los historiadores españoles han escrito". El yo narrativo lo sitúa como testigo primario y heredero de las historias fundacionales del incanato. La autoridad discursiva que edifica Garcilaso no sólo se justifica en "la leche que mamó”, sino, en los saberes de la histografía española sobre el incanato.

Garcilaso va más allá y argumenta que sus comentarios sólo servirían para aclarar la verdad que muchos cronistas intentaron decir. Verdades que, según Garcilaso, reflejan la credibilidad de los hechos históricos transcritos por aquellos, pero que por la falta del entendimiento del quechua- 
herramienta retórica distintiva en su crónica一, limitaron a los cronistas a un espejismo de la verdad. Garcilaso en primera persona señala que, "para atajar esta corrupción me sea lícito, pues soy indio, que en esta historia yo escriba como indio con las mismas letras que aquellas tales dicciones se deben escribir (p.17). La historia que implementa Garcilaso advierte el uso de alegorías que sólo él puede interpretar, alegando que el discurso oral del quechua se construye desde un lugar de enunciación restringido a los cronistas españoles. Sobre la autoridad discursiva que construye Garcilaso, Zamora apunta que "Garcilaso slyly argued that not knowing Quechua and wanting to understand Andean culture was like not knowing Hebrew and wanting to understand the Bible" (p.147). Como bien lo señala Zamora, el conocimiento del quechua, que advierte Garcilaso, no sólo le brinda la autoridad de modificar, agregar o corregir la historia de los incas. También le facilita la acción de implementar un nuevo término para sus mitos fundacionales a las que bautiza en términos cristianos, como las fábulas historiales.

Según Giovanna Vivianna Arias Carbone, en "Fábulas historiales y verdades teológicas: la preparación evangélica en los Comentarios reales de los Incas", el fruto de la convergencia de la tradición oral incaica y la tradición renacentista jesuita hizo posible que Garcilaso encontrase la manera de narrar los mitos andinos y reescribir o reinterpretar las acciones de los Incas (p.6). La propuesta que ofrece Arias Carbone claramente puede ser justificada en las herramientas retóricas que usa Garcilaso y su conexión con el mundo de los Incas, el del Perú de la conquista y el cosmos europeo. 
Reescribiendo la historia de la conquista española: Mitos fundacionales en los Comentarios Reales de LOS INCAS

Por otro lado, Arias Carbone propone el uso de fábulas historiales para analizar los relatos del imaginario incaico justificándose en la terminología curiosamente usada por Garcilaso cuando se refiere a mitos incaicos como fábulas historiales ${ }^{2}$. La interpretación que ofrece, basada en la historicidad de las fábulas, plantea que los Comentarios Reales de los Incas son la perfecta convergencia entre la ficción y la historia. El argumento de Arias Carbone parte de una lectura detallada de algunos pasajes de los Comentarios Reales como el siguiente:

Iremos con atención de dezir las hazañas más historiales, dexando otras muchas por impertinentes y prolixas, y aunque algunas cosas de las dichas y otras que se dirán parezcan fabulosas, me paresció no dexar de escrevirlas por no quitar los fundamentos sobre que los indios ${ }^{3}$ se fundan para las cosas mayores y mejores que de su Imperio cuentan. Porque, en fin, destos principios fabulosos procedieron las grandezas que en realidad de verdad possee hoy España.

(p.50)

A partir de la lectura de este pasaje, Arias Carbone argumenta que para incluir el pasado milenario de los Incas y lograr un final moralizante, Garcilaso tiende a fusionar historias y fábulas mediante un mecanismo intertextual al que llama fábula historial. Para Arias Carbone "la fábula historial es el mecanismo que le permitió [a Garcilaso] valorar ambas

2 Refiérase al Capítulo XVIII cual Garcilaso titula "De fábulas historiales del origen de los Incas" (p.53).

3 Mi énfasis 
nociones [la historia y la fábula] desde un único discurso. [...] De este modo, la fábula se convierte en el gran receptáculo de verdades alegorizadas sobre los antepasados andinos del Inca" (p.21). Sin embargo, su lectura parece no leer "aunque algunas cosas de las dichas y otras que se dirán parezcan fabulosas, me paresció no dexar de escrevirlas". Cuando Garcilaso, escribe "parezcan fabulosas" y "me paresció", el uso del verbo parecer no implica que la verdad de los narrado sea una verdad o una mentira. Garcilaso presenta lo fabuloso tal cual: una realidad que puede ser interpretada como histórica o como una fábula de un mundo nuevo y diferente, pero que sin embargo entre líneas simboliza un mito o un discurso oral ya difundido durante el auge del imperio incaico.

El relato de Manco Cápac y Mama Ocllo, cual Garcilaso denomina como una fábula historial, cuenta que el dios sol mandó a sus dos hijos a la tierra para que funden una civilización y rescatasen a los indios salvajes de la barbaridad. Garcilaso escribe que:

Ellos salieron de Titicaca y caminaron [...] doquiera que paraban, tentaban hincar la barra de oro y nunca se les hundió. Así entraron en una venta o dormitorio pequeño [...] que hoy llaman Pacárec Tampu. [...] Es uno de los pueblos que este príncipe mandó poblar después, y sus moradores se jactan hoy grandemente del nombre $e^{4}$, porque lo impuso nuestro Inca ${ }^{5}$. (p.4950)

\footnotetext{
4 Mi énfasis

5 Mi énfasis
} 
Después de este pasaje Garcilaso narra el descubrimiento del lugar designado, la domesticación de los indios salvajes y la fundación del imperio incaico en el Cusco. Lo resaltante de este pasaje no es sólo que la historia narrada por Garcilaso "significantly bestows the "honor" of recounting the mythical origin of the Incas upon one of his own noble relatives" (WeyGómez, p.9), sino que reconoce la existencia del lugar mítico, el Pacárec $\mathrm{Tampu}^{6}$ del que hoy produce la jactancia de muchos. Una jactancia que no sólo existe en el imaginario del imperio, sino también en una realidad palpable y que corrobora el mito escuchado durante su niñez y adolescencia. Garcilaso valiéndose de su linaje incaico narra una historia que "mejor que se sepa por las propias palabras que los Incas lo cuentan que no por las de otros autores extraños" (p.47). La transmisión de las historias, o a los que llamo mitos fundaciones, tienen sus propias leyes y un propio imaginario que edifica y validan sus particulares realidades o veracidades de los mitos contados.

¿Fue casualidad que Garcilaso narre la presencia física de Pacárec Tampu después de contar una "fábula historial"? No es insensato plantear que la posición de Garcilaso como historiador y mestizo en el mundo de las letras europeas lo hayan llevado a escribir: "Yo no me entremeto en cosas tan hondas; digo llanamente las fábulas historiales que en mis niñeces oí a los míos; tómelas cada uno como quisiere y déles la alegoría que más le cuadrare” (p.54). La crónica era destinada al lector europeo y por lo tanto

6 Lugar que hoy se conoce como Pacaritambo 
Garcilaso debía controlar la terminología que usaba para contar la historia y los orígenes del imperio incaico. El paralelismo que Garcilaso propone entre el imperio romano y el incaico puede ser interpretado como una herramienta retórica que explicase los elementos fabulosos presentes en la historia incaica.

Garcilaso argumenta que "el Cozco, en su Imperio, fue otra Roma en el suyo, y así se puede cotejar la una con la otra porque se asemejan en las cosas más generosas que tuvieron. La primera y principal, en haber sido fundadas por sus primeros Reyes" (p.350). Este análisis y la hipótesis de que el imperio incaico y romano fueran semejantes le permiten narrar historias fabulosas y mitologías sobre la fundación del imperio incaico. Los Comentarios Reales de los Incas y su veracidad también se justifica en su cercanía con las formas historiales en cómo se transcribieron la historia del imperio romano por sus cronistas. Según Sara Castro Klarén en su libro The Narrow Pass of Our Nerves: Writing, Coloniality and Postcolonial Theory (2011), Garcilaso "drawing on the organizing principle of the Roman historians [...] places the stones that together amount to the rebuilding of the Inca Empire" (p.148). Garcilaso recurre a la histografía del imperio romano para justificar el relato histórico del imperio incaico, que, aunque se construya a través de elementos fabulosos o míticos, también lo hizo el prestigioso imperio romano.

Así como el imperio romano tenía a un guía o tropheus (Espinos, p.11) encargado de la educación de los nobles y la difusión del conocimiento y la historia del imperio, también el imperio incaico contaba con pedagogos 
ReEscribiendo la historia de la conQuista española: Mitos fundaCionales en los COMENTARIOS REALES DE LOS INCAS

o amautas que eran responsable por la educación de la nobleza incaica y del aprendizaje de la historia, la religión, las ciencias y la cosmovisión del mundo andino (Larroyo, p.113). Sobre los amautas Garcilaso escribe que ellos "componían en verso las hazañas de sus Reyes y de otros famosos Incas y curacas principales, y los enseñaban a sus descendientes por tradición, para que se acordasen de los buenos hechos de sus pasados y los imitasen" (p.119). Si bien Garcilaso no se refiere a los relatos difundidos por los amautas sobre la fundación del imperio incaico y las hazañas de los habitantes como mitos, tampoco niega su carácter fundacional ni tradicional del imperio. La finalidad de divulgar historias, ya sean estas instruidas por los amautas o los tropheus, no era el de fabular, sino el de edificar una historia fundacional o mitológica de los orígenes.

Existe una tenue línea divisoria entre la significación de la fábula y el mito en un contexto del siglo decimosexto. De acuerdo con Efraín Kristal en su ensayo "Fábulas clásicas y neoplatónicas en los Comentarios reales de los Incas" señala que "sus fábulas [de Garcilaso] no son el producto de una imaginación libre de intenciones extraliterarias. Su significado reside, más bien, en su intención moral y teológica” (p.49). Una intención sobre todo teológica que no podía contradecirse a la autoridad bíblica del siglo XVI ni implementar mitos que no sean justificados por las leyes del discurso evangélico. Para Mircea Eliade, en su libro Mito y realidad (1991), el mito:

\footnotetext{
"cuenta una historia sagrada; relata un acontecimiento que ha tenido lugar en el tiempo primordial, el tiempo fabuloso de los «comienzos». Dicho de otro modo: el mito cuenta cómo, gracias a las hazañas de los Seres
} 
Sobrenaturales, una realidad ha venido a la existencia, sea ésta la realidad total, el Cosmos [...] Es, pues, siempre el relato de una «creación»: se narra cómo algo ha sido producido, ha comenzado a ser. El mito no habla de lo que ha sucedido realmente [...]. Los personajes de los mitos son Seres Sobrenaturales. Se les conoce sobre todo por lo que han hecho en el tiempo prestigioso de los «comienzos». (p.7)

Dentro de esta definición-el mito como una narración cosmogónica y su justificación en el discurso oral—los relatos de Manco Capac y Mama Ocllo encajan dentro de esta enunciación y no dentro de lo que se conoce como fábula. Según el Diccionario de Autoridades, se entiende por fábula al "cuento o narración de cosa que ni es verdad ni tiene sombra de ella, inventado para deléitar, yá sea con enseñanza o sin ella”. Esta definición se aleja del propósito que tienen los relatos "fabulosos" en la crónica de Garcilaso. Si hubiesen tenido ese fin, los relatos se apartarían de la justificación que tiene el cronista mestizo en hacer historia, y se acercarían a las fábulas populares contadas en la época. Las fábulas populares, como las de los viajeros, surgen de una creación anónima enraizada en los núcleos sociales y culturales y transmitidas por el discurso oral (Dido, p.3).

Las fábulas de viajeros, según el diccionario The Concise Oxford Dictionary of literary terms antes de la edad media ${ }^{7}$ ya eran conocidas por la población en general e innegablemente por los historiadores de la época. Garcilaso cita

7 Según el diccionario "The fable in Europe descends from tales attributed to Aesop, a Greek slave in the 6th century BCE: his fable of the fox and the grapes has given us the phrase 'sour grapes'. An Indian collection, the Bidpai, dates back to about 300 CE” (p.93). 
ReEscribiendo la historia de la conQuista española: Mitos fundaCionales en los COMENTARIOS REALES DE LOS INCAS

al padre José de la Acosta quien escribe sobre la llegada de un marinero a las Américas posiblemente antes que Cristóbal Colón. Según el relato, este marinero llevado por una tormenta había visto algún territorio del Nuevo Mundo. De la Acosta afirma que la historia nunca registró el nombre de este viajero y quizás fue debido a que este relato nació como una creación anónima y por ende de naturaleza fabulesca (Garcilaso, p.24). Durand, en el capítulo "Garcilaso el Inca, platónico", señala que Garcilaso es veraz en transmitir historias y relatos fabulosos tal y como son, sin comprometer la veracidad del relato (p.28) y lo que justificaría su "reconocimiento" de la veracidad de la crónica española. Garcilaso evidencia su autoridad de hablar de estos relatos apelando al yo narrativo y justificándose en el contacto que tuvo con su padre. Garcilaso dice: "yo las oí en mi tierra a mi padre y a sus contemporáneos, que en aquellos tiempos la mayor y más ordinaria conversación que tenían era repetir las cosas más hazañosas y notables que en sus conquistas habían acaecido" (p.23). Es claro que Garcilaso justifica su relato en su linaje español, pero lo destacable es que apela al conocimiento de la fábula popular para autorizarse doblemente como historiador del Viejo y del Nuevo Mundo.

Aunque el Diccionario de Autoridades no acuñe el término mito, ésteasociado con el mito del buen salvaje $e^{8}$ ya empieza a situarse en el mundo español en el siglo XV. Según Beatriz Fernández Herrero el término

8 Este mito alaba la naturaleza y las costumbres de los primitivos y ve en su estado natural el desconocimiento de las maldades de la civilización: la ambición, el odio y las desigualdades (Fernández Herrero, p.145). 
empezó a usarse poco después del descubrimiento de América y tan temprano como en 1493. La primera mención del término mito aparece en la crónica Década de Orbe Novo (1496) del humanista Pedro Mártir de Alegría, la cual es la primera crónica que cuenta la historia de las indias y es, en consecuencia, el comienzo de las visiones idílicas de los pueblos del nuevo mundo (p.146). Recuérdese que los Comentarios Reales de los Incas salió publicada por primera vez en 1609 , una diferencia de ciento dieciséis años después del trabajo de Alegría. La mención de la palabra mito no aparece en la crónica de Garcilaso, sin embargo, las alegorías de los fabulosos relatos del mito Manco Capac y Mama Ocllo apuntan a otra interpretación. ¿Por qué Garcilaso usa el término fábula historial a un relato que encaja dentro de las características del mito? Una de las posibles razones, la cual argumento en este análisis, por la cual Garcilaso decidió llamar a sus relatos fábulas históricas y no mitos es porque el mito ${ }^{9}$ conocido por los europeos, sobre la población del Nuevo Mundo, estaba relacionado con el mito del buen salvaje, aquel indio salvaje, que no era Inca.

A diferencia de Bartolomé de las Casas y su concepción del indio como pasivas ovejas y "género crio Dios los más simples, sin maldades ni dobleces, obedientísimas y fidelísimas" (p.2), Garcilaso tenía otra visión del indio ordinario y un proyecto disímil a lo que apunta Juan Ossio. Para Ossio, en su artículo "Los mitos de origen de los Incas en la construcción

9 Refiérase a la Brevisima relación de la destrucción de las Indias. 
Reescribiendo la historia de la conquista española: Mitos fundacionales en los Comentarios Reales de LOS INCAS

de los Comentarios Reales", Garcilaso usa la crónica para "forjar una defensa de los indígenas que deriva en una grandiosa utopía” (p.65). Sin embargo, si el proyecto histórico de Garcilaso hubiese sido forjar una defensa de los indios, no manifestaría que antes del establecimiento del imperio incaico, los indios eran salvajes, bárbaros, caníbales e idólatras de múltiples dioses. Sobre los habitantes antes del imperio, Garcilaso escribe que estos indios:

Sacrificaban hombres y mujeres de todas edades [...] La manera de este sacrificio de hombres y mujeres, muchachos y niños, era que vivos les abrían por los pechos y sacaban el corazón con los pulmones, y con la sangre de ellos, antes que se enfriase, rociaban el ídolo que tal sacrificio mandaba hacer [...] quemaban, en ofrenda para el ídolo, el corazón y los pulmones hasta consumirlos, y comían al indio sacrificado con grandísimo gusto y sabor y no menos fiesta y regocijo, aunque fuese su propio hijo. (p.41)

El mito del buen salvaje adquirió gran resonancia después de la publicación de la Brevisima Relación De La Destrucción De Las Indias (1552). A partir del trabajo de las Casas, el indio, el buen salvaje, fue gradualmente considerado un humano infantilizado que necesitaba la guía de la iglesia para civilizarse. Dentro de este contexto, Mercedes Cerna señala que para Garcilaso el principio de la civilización comienza con el final de los tiempos bárbaros, el inicio del incario y alcanza su auge con la llegada del cristianismo y las letras. "Garcilaso quiere que su pueblo (o al menos la élite) sea admitido sin asomo de duda entre los hombres" (p.42). Garcilaso crea distancias entre el imaginario del mito del salvaje y lo que él 
define como el imperio incaico. El uso del término fábulas historiales para describir el relato de Manco Capac y Mama Ocllo en vez del término mito explica su afán por crear diferencias entre la sociedad del indio común y la nobleza de su linaje. No es curioso notar que nuestro cronista usa el término de indígena ("forjar una defensa de los indígenas") en vez de indio para referirse a la historia fundacional y a los orígenes de los Incas. La diferencia de la terminología usada claramente distancia el mito del buen indio salvaje y las "fábulas historiales" del Inca indígena.

Ya sea llamado mito o leyenda, Garcilaso reescribe la historia del imperio Inca, sus inicios y los fundamentos de su edificación. El desarrollo de esta propuesta ha demostrado que el mito fundacional de Manco Capac y Mama Ocllo, así como en las fábulas de viajeros, forman parte de un proyecto fundacional de la historia y la mitología del incanato. Garcilaso no solo ofrece un relato opcional de la historia colonial del Perú, sino, valiéndose de la escritura en español y la oralidad quechua, reconfigura los discursos orales y escritos sobre la mitología Inca. El proyecto inscrito en el marco de la escritura de Los Comentarios reales de los Incas no son bifurcaciones de la ficción y la historia. La crónica de Garcilaso historiza el imaginario mítico del incanato y la historia de la invasión española a partir de la continua relación entre historia y mito. Esta relación le permita al primer cronista mestizo establecer un proyecto fundacional que ve en la autoridad de la mitología andina un componente esencial en la reescritura de su verdad histórica. 
ReEscribiendo la historia de la conQuista española: Mitos fundaCionales en los COMENTARIOS REALES DE LOS INCAS

\section{REEERENCIAS BIBLIOGRÁFICAS}

Baldick, Chris. The Concise Oxford Dictionary of Literary. Oxford (OUP), 1990.

Castro-Klarén, Sara. The Narrow Pass of Our Nerves: Writing, Coloniality and Postcolonial

Theory. Orlando, FL: Iberoamericana Vervuert Pub., 2011.

Chanady, Amaryll Beatrice. Latin American Identity and Constructions of Difference. n.p.:

Minneapolis: University of Minnesota Press, c1994., 1994. Univ. of Georgia Catalog. Web. 28 Apr. 2016

De las Casas, Bartolomé. Brevísima Relación de la Destrucción de las Indias. Buenos Aires: Editorial Universitaria De Buenos Aires, 1966.

Diccionario de Autoridades: 1726 - 1739. Boadilla del Monte (Madrid): JdeJ Ed., 2013. Nuevo

Diccionario Histórico del Español. Instituto Rafael Lapesa. Web. 30 Apr. 2016.

Dido, Juan Carlos. “Teoría de la Fábula." Espéculo: Revista de Estudios Literarios 41, 2009.

Durand, José. El Inca Garcilaso de América. Lima: Biblioteca Nacional Del Perú, 1988.

Espinos, Josefa. Asi vivian los romanos. Madrid: Anaya, 1994.

Fernández Herrero, Beatriz. "El mito del buen salvaje y su repercusión en el gobierno de Indias."(1989).

Kristal, Efraín. "Fábulas clásicas y neoplatónicas en los Comentarios Reales de los Incas."

Homenaje a José Durand. By José Durand and Luis Cortest. Madrid: Editorial Verbum, 1993.

Larroyo, Francisco. Historia general de la pedagogía. México: Editorial Porrúa, 1977. Hispanic American Periodical. Web. 30 Apr. 2016. 
Ossio, Juan. "Los mitos de origen de los Incas en la construcción de los Comentarios Reales "Entre la espada y la pared: El Inca Garcilaso de la Vega y sus Comentarios Reales. Lima: Fondo Editorial, 2010. p.57-72.

Vargas Llosa, Mario. "El Inca Garcilaso y la lengua de todos." Entre la espada y la pared: El Inca Garcilaso de la Vega y sus Comentarios Reales. Lima: Fondo Editorial, 2010. P.19-28.

Vega, Garcilaso de la. Comentarios reales de los Incas. Caracas: Biblioteca Ayacucho, 1976.

Wey-Gómez, Nicolás. "Nuestro Padre El Sol': Scholastic Cosmology and the Cult of the Sun in

Inca Garcilaso's 'Comentarios Reales.” Latin American Literary Review, vol. 26, no. 52, 1998, pp. 9-26. JSTOR, JSTOR, www.jstor.org/stable/20119782.

Zamora, Margarita. Language, Authority, and Indigenous History in the Comentarios Reales de los Incas. Cambridge: Cambridge UP, 1988. 